\title{
The Akt inhibitor KP372-I suppresses Akt activity and cell proliferation and induces apoptosis in thyroid cancer cells
}

\author{
M Mandal', S Kim', MN Younes', SA Jasser', AK El-Naggar², GB Mills ${ }^{3}$ and JN Myers*,I \\ 'Department of Head and Neck Surgery, The University of Texas MD Anderson Cancer Center, Houston, TX, USA; ${ }^{2}$ Department $f$ Pathology, \\ University of Texas MD Anderson Cancer Center, Houston, TX, USA; ${ }^{3}$ Department of Molecular Therapeutics, The University of Te, MD An 'erson
} Cancer Center, Houston, TX, USA

The phosphatidylinositol $3^{\prime}$ kinase (PI3K)/phosphatase and tensin homologue deleted on chromosom n/An., nnway, which is a critical regulator of cell proliferation and survival, is mutated or activated in a wide variety of cancers. Akt a sars to be a key central node in this pathway and thus is an attractive target for targeted molecular therapy. Wv 'emonstre ed that Akt is highly phosphorylated in thyroid cancer cell lines and human thyroid cancer specimens, and hypothesise nat, KP372-I, an Akt inhibitor, would block signalling through the PI3K pathway and inhibit cell proliferation while induciry ptosis of thyroid cancer cells. KP372-I blocked signalling downstream of Akt in thyroid tumour cells, leading to inhibition o vll p liferation and increased apoptosis. As thyroid cancer consistently expresses phosphorylated Akt and KP372-I effectively block. kt signalling, further preclinical evaluation of this compound for treatment of thyroid cancer is warranted. British Journal of Cancer (2005) 92, I 899- 1905. doi: I 0. I 038/sj.bjc.6602595 Published online 3 May 2005 (c) 2005 Cancer Research UK

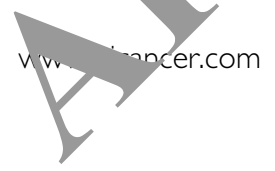

Keywords: molecular therapy; growth factors; anaplastic thyroid ncer; $172-1$

The incidence of thyroid cancer in the United States ic ected to be approximately 23600 in 2004 (Jemal et al, 2004). vroid carcinomas can be classified into papillary th yrord carci ha, follicular thyroid carcinoma, and anaplastic thyroid carcinoma (Jemal et al, 2004). The papillary and follicular yroid carcinomas constitute the majority of thyroid carcinoma $d$, grouped together as well-differentiated thyroid inomas. This group of thyroid carcinomas can often be cured witn 'al resection and with radioactive iodide therapy oweve there are no effective alternative therapies for patents rith $\mathrm{n}$ otastatic well-differentiated thyroid cancer who $\mathrm{a}_{4} \mathrm{o}^{+}$ad to radioactive iodine therapy, suggesting an argent ed for development of novel therapies.

The pathogenesis of roid cancer is characterised by the alterations of myituple signa $a_{\star}$ pathways and by abnormalities in a variety of me ur-suppressor genes and cell-cycle proteins (Fagin, 2002). 1 ctiva on of the Akt protein kinase B (Akt/PKB) signallin thwa, ar pears to play an important role in the devel rmen and p.ogression of thyroid tumours. Interestingly, Akt ha

*Correspondence: Dr JN Myers, Department of Head and Neck Surgery, Unit 44I, The University of Texas MD Anderson Cancer Center, I5I5 Holcombe Boulevard, Houston, TX 77030, USA;

E-mail: jmyers@mdanderson.org

This work was supported by The University of Texas MD Anderson Cancer Center Multi-Disciplinary Research Program in Thyroid Cancer and by The Golfers Against Cancer

Received 10 November 2004; revised 17 February 2005; accepted 24 March 2005; published online 3 May 2005 of phosphatase and tensin homologue deleted on chromosome ten (PTEN), a tumour-suppressor gene, in Cowden's syndrome, an autosomal dominant multi-organ hamartoma syndrome characterised by benign and malignant thyroid tumours and breast and colon cancers (Dahia et al, 1997; Liaw et al, 1997). Akt activation, probably through a variety of mechanisms including aberrant stimulation of upstream cancers, occurs in most sporadic thyroid cancers (Ringel et al, 2001). In benign thyroid cell models, Akt signalling is important for cell growth in response to insulin, insulin-like growth factor-1, and serum (Kimura et al, 1999, 2001; Coulonval et al, 2000; Saito et al, 2001) and is activated by several oncogenes involved in thyroid cancer, including activated $p 21^{\text {ras }}$ and chimeric rearrangements involving the ret gene (RET/PTC oncogenes) (Borrello et al, 1994; Rodriguez-Viciana et al, 1994). Despite the central role for Akt activation in thyroid tumorigenesis, little is known about the biological effect of inhibition of the Akt kinase in the progression of thyroid carcinoma.

Based on the putative central role of the Akt kinase in thyroid oncogenesis, we hypothesised that KP372-1, a specific Akt kinase inhibitor (molecular weight, 224.20; QLT Inc., Vancouver, BC, Canada), would inhibit the proliferation and induce apoptosis of thyroid cancer cells in vitro. KP372-1 was identified in a screen of kinase-inhibiting compounds tested on more than 100 different cellular kinases, and was selected for its high specificity for the Akt kinase (unpublished data from QLT). In this study, we demonstrated the key role of the phosphatidylinositol-3 kinase (PI3K)/ Akt pathway in thyroid cancer and explored the effect of KP372-1 using thyroid cancer cells as model systems. We assessed the effects of KP372-1 on the inhibition of the PI3K/Akt pathway biochemically and on cell proliferation and apoptosis. 


\section{MATERIALS AND METHODS}

\section{Cell lines}

A papillary thyroid carcinoma cell line, NPA187, a follicular thyroid cancer cell line, WRO, and anaplastic thyroid cancer cell lines KAT4, C643, K18, HTH74, ARO, and DRO were used. NPA187 and WRO were obtained from Dr Yan Oh, The University of Texas MD Anderson Cancer Center, Houston, TX, USA, and KAT4, C643, K18, HTH74, and DRO were obtained from Dr Sai-Ching Jim Yeung, Department of Endocrine Neoplasia and Hormonal Disorders, MD Anderson Cancer Center, Houston, TX, USA. All the cell lines were grown in RPMI medium supplemented with $10 \%$ foetal bovine serum, L-glutamine, penicillin, sodium pyruvate, nonessential amino acids, and vitamin solution (Life Technologies, Inc., Grand Island, NY, USA). Adherent monolayer cultures were maintained on plastic and incubated at $37^{\circ} \mathrm{C}$ in $5 \%$ carbon dioxide and $95 \%$ air. The cultures were free of Mycoplasma species. The cultures were maintained no longer than 12 weeks after recovery from frozen stocks.

\section{Compounds}

KP372-1 (Figure 1) was synthesised by QLT Inc., Vancouver, BC, Canada. KP372-1 is a mixture of two isomers present in approximately equal amounts. A stock solution of KP372-1 for enzyme or cellular assays was prepared in dimethyl sulphoxide (DMSO) and then diluted in the medium. The final concentration of DMSO in the incubation mixture did not exceed $0.1 \% \mathrm{vv}^{-1}$.

\section{Tissue samples and Western blotting}

Fresh frozen human thyroid tissue specimens were obtained from the thyroid tissue bank (The University of Texas MD Anderson Cancer Center) with the approval of the Institutional Review soard at the MD Anderson Cancer Center. Thyroid specime fro $n$ patients who had undergone surgery were carefully h-vest by an experienced pathologist (AKE) and were snap fr on in liq. nitrogen and stored at $-80^{\circ} \mathrm{C}$. Thawed tissu sa les were homogenised in Triton X-100 lysis buffer $\left(20 r\right.$ Y $\mathrm{HEP}_{\llcorner} \quad 59 \mathrm{~mm}$

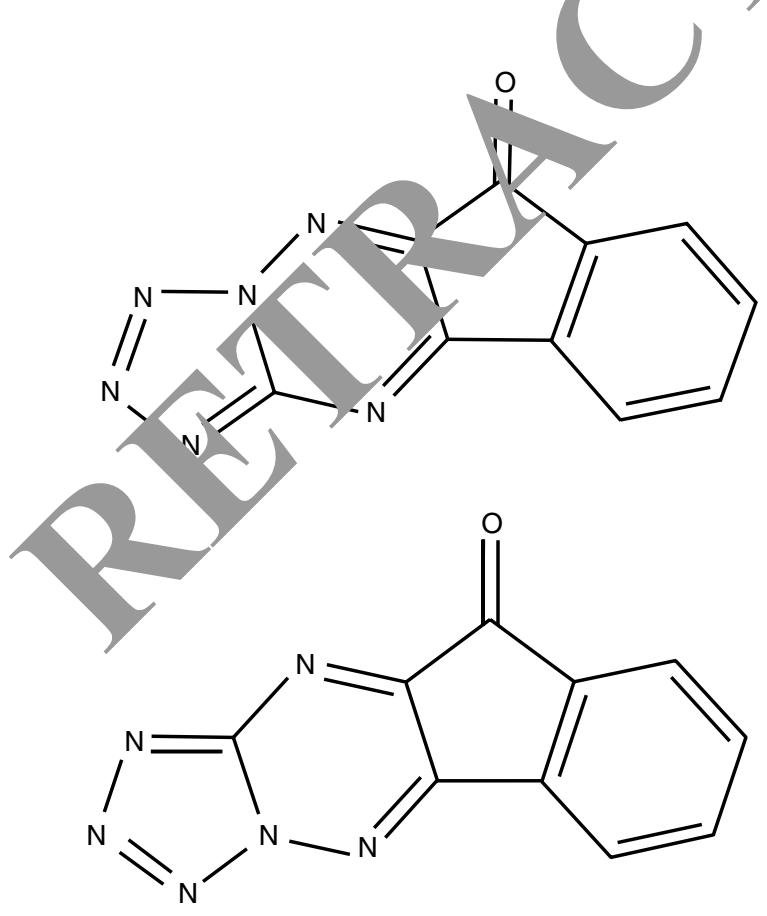

Figure I Molecular structure of KP372-I.
$\mathrm{NaCl}, 1 \%$ Triton X-100, 0.1\% deoxycholate, 2 mm EDTA, $2 \mathrm{~mm}$ sodium vanadate, and protease inhibitor cocktail), and equal amounts of protein were analysed by Western blotting. The following antibodies were used for Western blotting: rabbit antipAkt (S473), rabbit anti-pAkt (T308), and rabbit anti-Akt (Cell Signaling, Beverly, MA, USA), rabbit anti-p85 and rabbit antiPTEN (Santa Cruz, Santa Cruz, CA, USA), and rabbit anti- $\beta$-actin (Sigma, St Louis, MO, USA). $\beta$-Actin was used as a loading control.

\section{Cell proliferation}

For MTT assays involving treatment with KP372 the cells were diluted to 1000 cells per $100 \mu \mathrm{l}$ of complete mediun rom hich $100 \mu \mathrm{l}$ was added to each well of a 96-well plate (Falce BectonDickinson, Franklin Lakes, NJ, USA). On followil g day, $100 \mu \mathrm{l}$ of medium supplemented with two time the ired oncentration of KP372-1 was added to the approp rate wells. cells were then kept at $37^{\circ} \mathrm{C}$ in $5 \% \mathrm{CO}_{2}$ for $72 \mathrm{~h}$. At his point $10 \mu \mathrm{l}$ of a $5 \mathrm{mg} \mathrm{ml}^{-1}$ stock solution of MTT (Sigm 7 dis ved in water was added to each well, and the plates were urn w the $37^{\circ} \mathrm{C}$ incubator for $2 \mathrm{~h}$. The supernatant was aspirat ut of each well, and $200 \mu \mathrm{l}$ of DMSO was added to $f_{a}$ well. Th plates were then shaken for $5 \mathrm{~min}$ and the optical a ity measured at $570 \mathrm{~nm}$ using a spectrophotomete

To measure the 11 proliferation, we plated the NPA187 and WRO cells at ation of $1 \times 10^{4}$ cells well $^{-1}$ in six-well plates. The cells $\mathrm{w}$ then treated with KP372-1 at a concentration of 30 an $n$ nM for .PA187 and WRO cell lines, respectively, and were courteu $\delta$ a haemocytometer on days 1,2 , and 3.

\section{thymid he incorporation}

DN synthesis in the control and KP372-1-treated cells was sse sed by the incorporation of ${ }^{3} \mathrm{H}$-thymidine into newly licated DNA. NPA187 and WRO cells were plated at a concentration of 5000 cells well $^{-1}$ in 96 -well plates. After $24 \mathrm{~h}$, the cells were treated with different concentrations of KP372-1 for $48 \mathrm{~h}$ and treated with $5-\mu \mathrm{Ci} \mathrm{ml}^{-13} \mathrm{H}$-thymidine during the last $2 \mathrm{~h}$ (NEN Life Science Products, Inc., Boston, MA). Cells were washed with PBS and then extracted with $0.1 \mathrm{~N} \mathrm{KOH}$ and counted by liquid scintillation.

\section{DNA fragmentation assay}

For the DNA fragmentation assay, low-molecular-weight DNA was prepared (Mandal et al, 1996). Briefly, NPA187 and WRO cells $\left(3 \times 10^{6}\right.$ per plate $)$ were seeded in $100 \mathrm{~mm}$ plates and treated with KP372-1 (30 nM for NPA187 and $60 \mathrm{nM}$ for WRO) for 1, 2, or 3 days. Both floating and attached cells were scraped and collected in medium, washed three times with PBS, and resuspended in $1 \mathrm{ml}$ of lysis buffer (20 mM Tris- $\mathrm{HCl}$ (pH 8), $10 \mathrm{~mm}$ EDTA (pH 8), and 0.5\% Triton X-100). After incubation on ice for $30 \mathrm{~min}$, the lysates were spun at $12000 \mathrm{rpm}$ in a microcentrifuge for $10 \mathrm{~min}$. Lowmolecular-weight DNA in the supernatant was extracted with equal volumes of phenol and chloroform for $1 \mathrm{~h}$ at $4^{\circ} \mathrm{C}$. Ammonium acetate $(2 \mathrm{M})$ was added to the aqueous phase, and the DNA was precipitated with two volumes of ethanol at $-20^{\circ} \mathrm{C}$ overnight. The DNA was treated with RNAse $\mathrm{A}\left(1 \mathrm{mg} \mathrm{ml}^{-1}\right)$ at $37^{\circ} \mathrm{C}$ for $1 \mathrm{~h}$, and total DNA was analysed using $1.5 \%$ agarose gel and visualised with ethidium bromide staining.

\section{Western blot analysis of thyroid carcinoma cell lines after treatment with KP372-1}

In order to show the induction of apoptosis-related proteins by KP372-1, NPA187 and WRO cells $\left(3 \times 10^{6}\right.$ per plate) were seeded in $100 \mathrm{~mm}$ plates and treated with KP372-1 (30 nM for NPA and $60 \mathrm{nM}$ for WRO) for 1, 2, or 3 days. Both floating and attached cells were 
scraped and collected in medium, washed three times with PBS, and the cells were lysed in Nonidet P-40 lysis buffer (50 mM Tris$\mathrm{HCl}$ ( $\mathrm{pH} 8.0$ ), $137 \mathrm{~mm} \mathrm{NaCl}, 10 \%$ glycerol, $1 \%$ Nonidet P-40, $50 \mathrm{~mm}$ $\mathrm{NaF}, 10 \mathrm{~mm} \beta$-glycerol phosphate) containing $1 \mathrm{~mm}$ sodium vanadate, $1 \mathrm{~mm}$ phenylmethylsulphonyl fluoride, $10 \mu \mathrm{g} \mathrm{ml}^{-1}$ apoptinin, and lysis buffer (20 mM Tris- $\mathrm{HCl}(\mathrm{pH} 8), 10 \mathrm{~mm}$ EDTA (pH 8 ), and $0.5 \%$ Triton X-100). After incubation on ice for $30 \mathrm{~min}$, the lysates were spun at $12000 \mathrm{rpm}$ in a microcentrifuge for $10 \mathrm{~min}$. Equal amounts of protein were then analysed by Western blotting using the following antibodies: mouse anti-poly(ADP-ribose)polymerase (PARP) antibody (Trevigen, Gaithersburg, MD, USA), rabbit anti-caspase- 3 antibody (Cell Signaling), and rabbit anti- $\beta$ actin antibody (Sigma). $\beta$-Actin was used as a loading control.

In order to show the effect of KP372-1 on various signal transduction pathways in thyroid carcinoma cell lines, we performed Western blot analysis on NPA187 and WRO cells after treating the cells with KP372-1. The cells were plated as described above. After treating the cells with KP372-1 (30 nM for NPA187 and $60 \mathrm{nM}$ for WRO) for $4 \mathrm{~h}$, both floating and attached cells were scraped and collected in medium, washed three times with PBS, and lysed with a lysis buffer as described above. After incubation on ice for $30 \mathrm{~min}$, the lysates were spun at $12000 \mathrm{rpm}$ in a microcentrifuge for $10 \mathrm{~min}$. Equal amounts of protein were then analysed by Western blotting using the following antibodies: rabbit anti-pAkt (S473), rabbit anti-Akt, rabbit anti-p-mitogen-activated protein kinase (MAPK), rabbit anti-pmTOR, rabbit anti-pS6R, and rabbit anti-S6R (Cell Signaling).

\section{Akt enzyme assay to detect in vitro kinase activity}

Cells were lysed using the lysis buffer provided in the Akt enzyme assay kit (Cell Signaling). The cells were scraped and placed in an Eppendorf centrifuge tube incubated on ice for $15 \mathrm{~min}$ and spun in a centrifuge at $4{ }^{\circ} \mathrm{C}$ for $15 \mathrm{~min}$ at full speed. The lysates were then transferred to a new tube and stored at $-80^{\circ} \mathrm{C}$ until assayed

Immunoprecipitation was carried out as follows: $500 \mu \mathrm{g}$ protein was added to $5 \mu$ l of anti-Akt antibody (Cell Sigr ling) an rotated at $4{ }^{\circ} \mathrm{C}$ overnight. Protein A sepharose bead ( 1 l) were then added and rotated for $3 \mathrm{~h}$ at $4^{\circ} \mathrm{C}$. The prote $i \mathrm{~A} \mathrm{se}_{\mathrm{h}}$ rose beads were then washed three times with lysi, buffer and, Iree times with the $1 \times$ kinase buffer provided i the kit. Then the beads were aspirated, and $40 \mu \mathrm{l}$ of kinase buffe ras sup lemented with $200 \mu \mathrm{m}$ ATP and a mixture $(1 \mu \mathrm{g}$ per $40 \mu \mathrm{l}$, olon protein (provided in the kit). The tubes were $\mathrm{t}$ incubated at $30^{\circ} \mathrm{C}$ for $30 \mathrm{~min}$, after which $20 \mu \mathrm{l}$ of $3 \times$ sample $\mathrm{v}$. er consisting of $187.5 \mathrm{~mm}$ Tris- $\mathrm{HCl}(\mathrm{pH} 6.8), 6 \% \mathrm{v}^{-1}$ ) s dium dodecyl sulphate (SDS), $30 \%$ glycerol, $150 \mathrm{~mm}$ TT, nd $0.0 \%\left(\mathrm{wv}^{-1}\right)$ bromophenol blue was added to earh th. $5 \mathrm{~min}$ at $95^{\circ} \mathrm{C}$, and glycogen vnthetase kinase-3 (GSK-3) phophorylation was $\mathrm{m}_{\mathrm{t}}$ ured us.ng phospho antibodies (Cell Signaling).

\section{RESULTS}

Akt : vho -horylated in many thyroid cancer cell lines

In an ats $\mathrm{nt}$ to delineate the role of Akt signalling in thyroid cancer cells, we first profiled the expression of pAkt, total Akt, and the p85 subunit of PI3K in a panel of thyroid cancer cell lines. As seen in Figure 2, most thyroid cancer cell lines expressed readily detectable levels of pAkt-Ser473, pAkt-Thr308, total Akt, and subunits of the PI3K p85. PTEN was present in all the cell lines. The low levels of pAkt in some cell lines was likely due to the relative levels of pAkt rather than complete absence of this molecule. Three cell lines were selected for further characterisation: NPA187, which expressed relatively high levels of pAkt, and total Akt, K18, which expressed high levels of pAkt and low levels of total Akt, and WRO, which expressed lower levels of pAkt with high levels of total Akt. The presence of similar amounts of PTEN (most mutant PTEN molecules are unstable) in these cell lines suggests that the difference in pAKT levels was likely not due to defective PTEN function.

\section{Akt expression in human thyroid cancer tissues}

After profiling the expression of Akt and pAkt in thyroid cancer cell lines, we focused our attention on the role of $\mathrm{Al}^{-}$in welldifferentiated thyroid carcinoma in subsequent exp riments. To determine whether our in vitro findings with cell lines T.ced he biology of human thyroid cancer in vivo, we eval ed the expression of Akt and pAkt in fresh papil ry thyroid amour specimens using Western blotting. The status $\mathrm{kt}$ acti ation was examined using a phosphorylation-specinc antib a ainst pAktSer473 and antibody against total $\mathrm{A} t$ in thyroic tumours and adjacent normal-appearing tissues. A shown in Figure 3, six of eight tumours had higher leve of nh rylated Akt-Ser473 than did normal tissues des ite ilar levels of total Akt. Akt phosphorylation was high in the roid tumours than in the neighbouring normal ti suc uggesting a potential role for Akt phosphorylation in the carcino nesis of thyroid cancer. The high levels of Akt phospico ation in eighbouring tissue samples from some patients $m$ refl a 'field effect' due to genetic aberrations or, alternatively, $t_{1}$ proauction and action of paracrine growth factors by the tumou.

KP372-1 inh bits proliferation and induces the apoptosis of th id canc $-\mathrm{r}$ cells in vitro

The et t of KP372-1 on the growth of NPA187 and WRO cells was 'uat d using an MTT assay, cell counting, and ${ }^{3} \mathrm{H}$-thymidine inc poration. The proliferation of these cell lines was inhibited by I P372-1 with an $\mathrm{IC}_{50}$ (concentration at which $50 \%$ inhibition occurs) of 30 and $60 \mathrm{nM}$ for NPA187 and WRO, respectively (Figure 4). The proliferation of the cell lines was also inhibited by KP372-1, as evidenced by cell counting (Figure 5A and B) and the ${ }^{3} \mathrm{H}$-thymidine incorporation assay (Figure $5 \mathrm{C}$ and $\mathrm{D}$ ). As shown in Figure 2, different levels of pAkt and total Akt were seen in the three cell lines. As shown in Figure 4, the NPA187 cell line, which had high basal pAkt levels, was more sensitive to KP372-1 than was WRO, which had low pAkt levels, suggesting that high pAkt could indicate cell dependence on this pathway and thus higher sensitivity to the inhibition of Akt.

This decreased MTT incorporation can be due to a decreased rate of cell cycle transit or increased cell death. To assess the latter possibility, we treated the NPA187 and WRO cells with KP372-1 for different lengths of time and determined the extent of apoptosis by DNA fragmentation (Figure $6 \mathrm{~A}$ ) and the accumulation of a sub- $\mathrm{G}_{0} /$ $\mathrm{G}_{1}$ cell population by flow cytometry (data not shown). The effect of KP372-1 on the status of PARP and caspase- 3 was also examined (Figure 6B). The induction of activated caspase- 3 and cleavage of PARP by KP372-1 treatment were observed in both cell lines, although with different kinetics and different magnitudes. Consistent with the MTT data, NPA187 demonstrated greater degrees of PARP cleavage and DNA degradation at 72 hours than WRO.

To determine the duration of exposure to KP372-1 required to commit cells to apoptosis, NPA187 and WRO cells were incubated with 30 and $60 \mathrm{nM}$ of KP372-1, respectively, for $6 \mathrm{~h}$ in serum-free medium. The cells were then washed with PBS and grown in medium containing 10\% FBS without the inhibitor for another 24 or $48 \mathrm{~h}$. The cells were then assayed for the percentage of apoptotic cell death. Apoptosis was not induced under these conditions (data not shown). Thus, we concluded that KP372-1 must be present continuously in order to induce apoptosis at least at these doses and for these cell lines. 


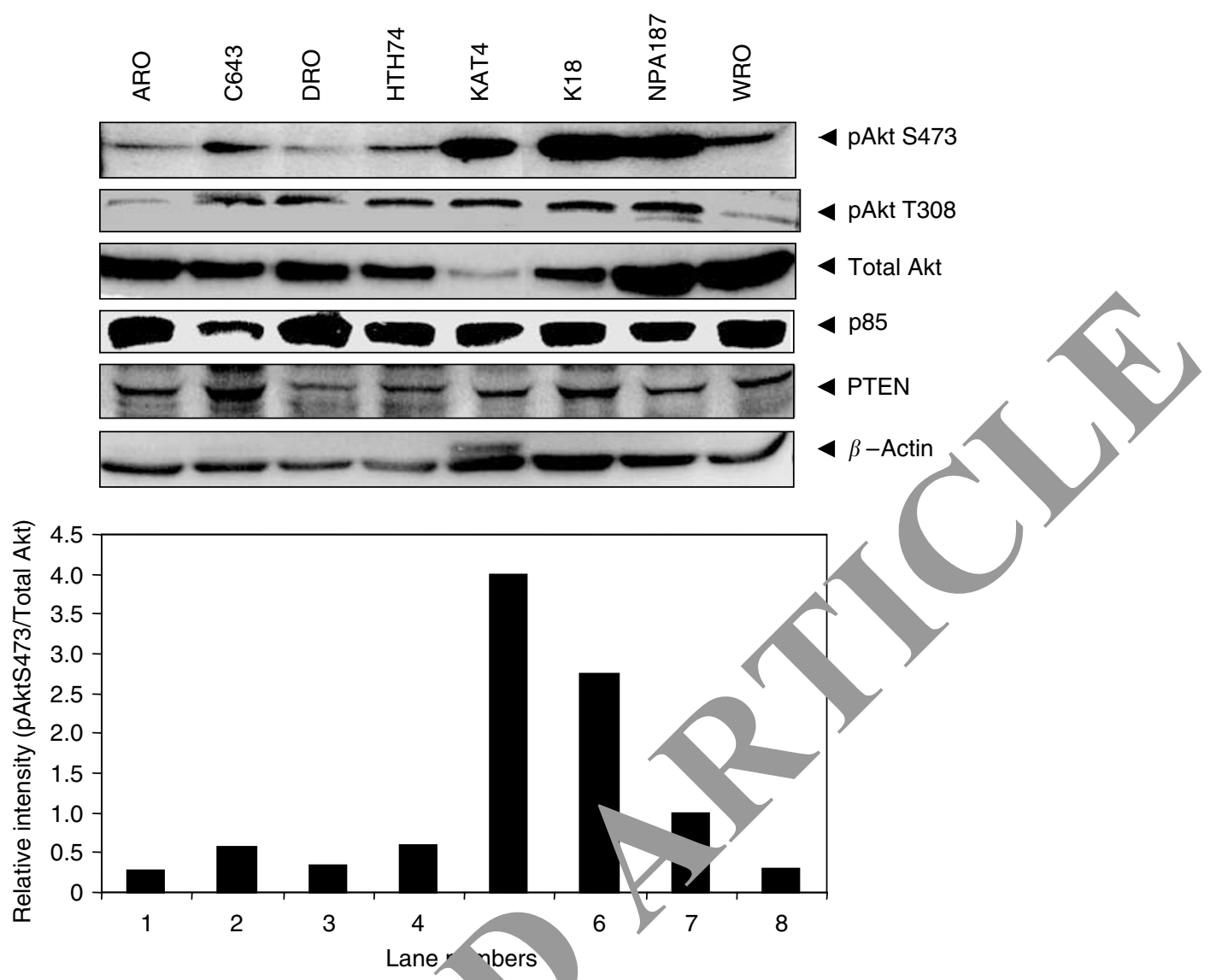

Figure 2 Expression of phosphorylated (p) Akt-Ser473, pAkt-Throfs, p8s bu its of PI3K, and PTEN in thyroid cancer cell lines. Cell lysates from exponentially growing cells were analysed by immunoblotting wit antibodies a inst the indicated proteins. Results shown are representative of three independent experiments.
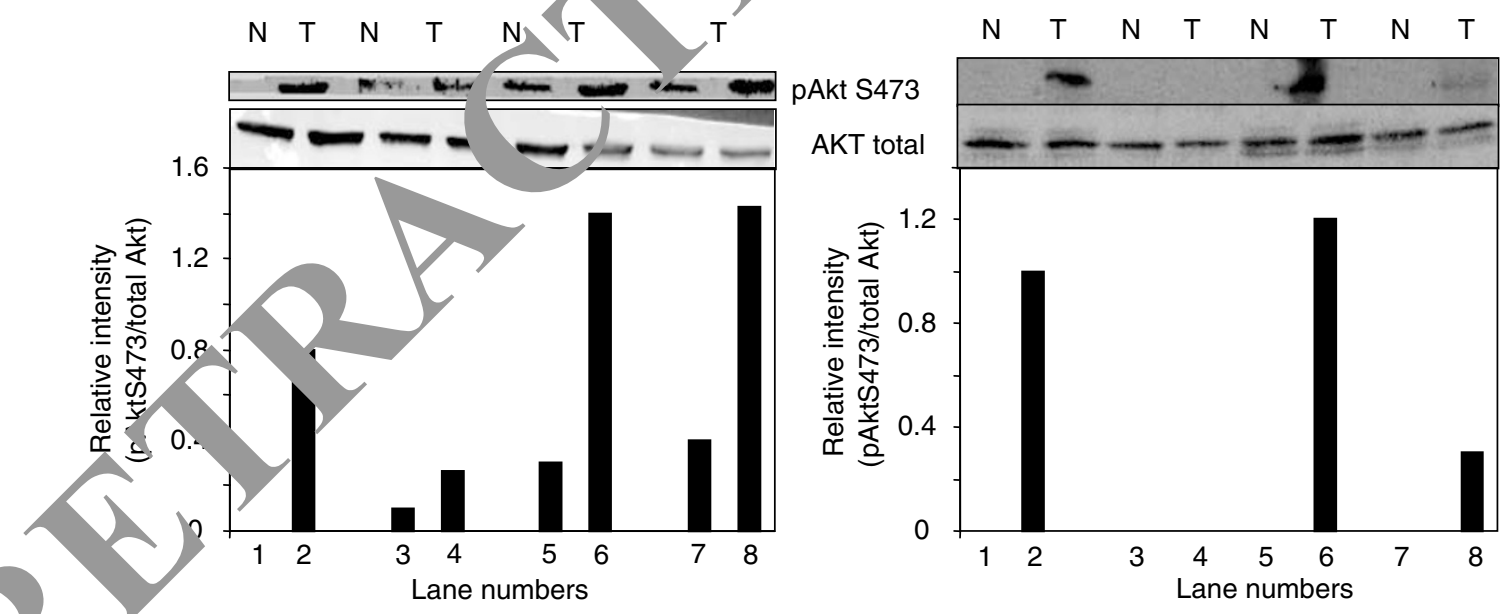

Fig. 3 -xpressions in human thyroid cancer. Expression of pAkt (Ser473) and total Akt in thyroid tumours ( $\mathrm{T}$ ) and adjacent normal tissues (N) were a ted with immunoblotting.

KP372-1 inhibits Akt kinase activity, phosphorylation of Akt, and downstream targets of Akt in thyroid cancer cells

We next determined the effect of KP372-1 on the phosphorylation of AKT (Ser473) and on downstream targets of Akt, including p-mTOR and p-S6 ribosomal protein (Ser240/244), and MAPK. We treated NPA187 and WRO cells with KP372-1 at their respective $\mathrm{IC}_{50}$ for $4 \mathrm{~h}$ and analysed the cell lysates with the specific antibodies indicated in Figure 7A. In the case of NPA187 and WRO, phosphorylation of Akt and S6 ribosomal protein was downregulated by treatment with KP372-1. However, the phosphorylation of MTOR and MAPK was not changed by treatment with KP372-1. Akt kinase activity was also downregulated by KP372-1 in multiple thyroid cancer cell lines, as tested by an in vitro kinase assay using GSK- $\beta$ as substrate (Figure 7B). 


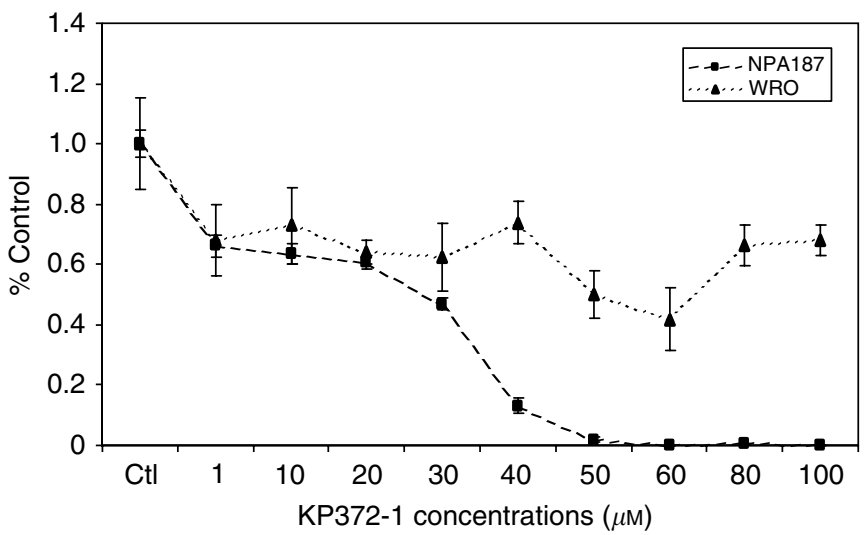

Figure 4 Effects of KP372-I on the proliferation of thyroid carcinoma cell lines in vitro. Thyroid carcinoma cell lines NPAI87 and WRO were plated in a 96-well plate and treated with different concentrations of KP372-I for $48 \mathrm{~h}$. Cell growth was measured by MTT assay. Results shown are representative of three experiments.

Our results indicate that KP372-1 blocks Akt kinase activity, thereby decreasing phosphorylation of the S6 ribosomal protein. The mechanism resulting in the decrease in Akt phosphorylation is under exploration, but may represent an allosteric change in the molecule, decreasing access to upstream kinases or increasing access to downstream phosphatases.

\section{DISCUSSION}

Our study shows that thyroid cancer cells expressed detectab'. levels of Akt Ser473, Akt-Thr308, total Akt, PTEN, and the 085 subunits of the PI3K and Akt kinase activity. Most of the tum showed a higher level of Akt-Ser473 phosphorylation tha matching normal tissues, suggesting an associatior tween a high level of Akt phosphorylation and thyroid carcinugent This association was further supported by evidence th $\mathrm{at}$ Drockade $\mathrm{akt}$ signalling with the selective inhibitor KP372- 1 induced apoptosis and inhibited cell proliferation in human thyr cancer cell lines in culture. Furthermore, KP372-1 was fou to nhibit the phosphorylation and kinase activities $1 \mathrm{kt}$ in addition to the phosphorylation of downstream substrat s. Jer, the mechanism responsible for decreased $\mathrm{A}^{1}$ is possible that the binding of ?372-1 to Akt may alter its conformation so that the $\mathrm{re}$ ar -acid residues are not available for phosphoryl a10n. A milar effect has been seen with other inhibitors sucb those to MEK1 and JNK where they decrease phosphoryn tion their target in cells with an activated pathway.

In our stud we found that the papillary thyroid cancer cell line NPA187 was $n$. sens ive to the effects of KP372-1 compared with the "icula. 11 /ine WRO. However, Ringel et al (2001) found hat e cell me NPA187 was more sensitive than WRO to the efi -94002, a phosphatidylinositol $3^{\prime}$ kinase (PI3K) inhibitor. his difference in sensitivities to two different agents that target ne same pathway may be due to the fact that these agents show affinity for kinases other than the intended primary target kinase. It is also known that KP372-1 inhibits kinases other than Akt, such as CDK1, CK2, CSK, DNAPK, ERK1, GSK3b, LCK, MEK1, PIM, PKA, PKC, and S6K, albeit at relatively high concentrations (unpublished work from QLT). We have also found that the NPA187 cell line showed higher levels of Akt phosphorylation than WRO. This observation suggests that NPA187 may be more dependent than WRO on the activation of Akt for survival and proliferation.
A 120

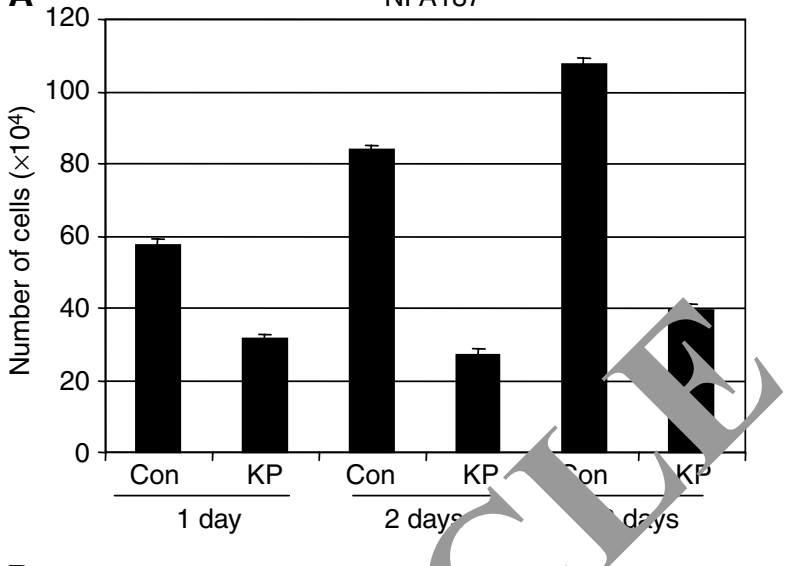

B
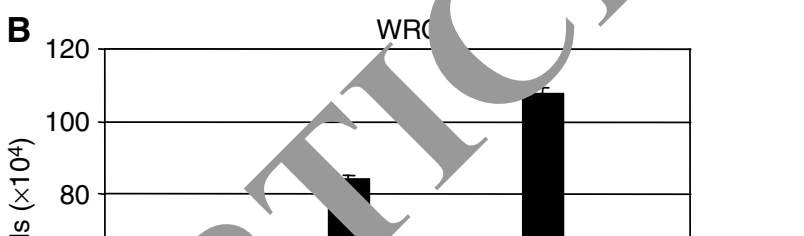

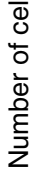
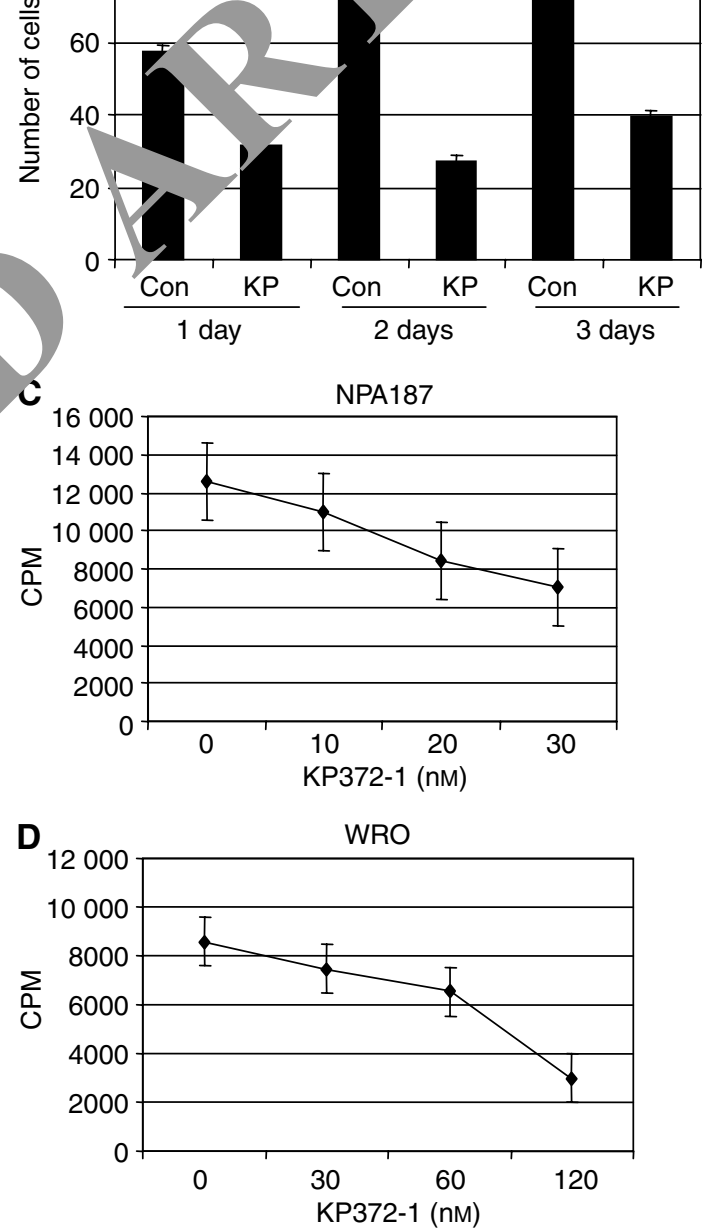

Figure 5 Effects of KP372-I on the proliferation of thyroid carcinoma cell lines in vitro. (A, B) Thyroid carcinoma cell lines NPAI 87 and WRO were plated in six-well plates and treated with 30 and 60 nM KP372-I for NPAI87 and WRO cell lines, respectively, for 1, 2, or 3 days. Cell proliferation was then measured by cell counting using a haemacytometer. (C, D) Thyroid carcinoma cell lines NPAI 87 and WRO were plated in a 96-well plate and treated with various concentrations $(0-120 \mathrm{~nm})$ of KP372-I for $48 \mathrm{~h}$. Cell proliferation was then measured by ${ }^{3} \mathrm{H}$-thymidine incorporation. Results shown are representative of three experiments. 
A

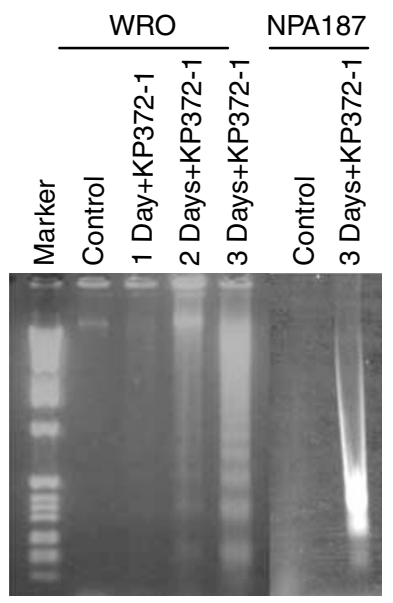

B

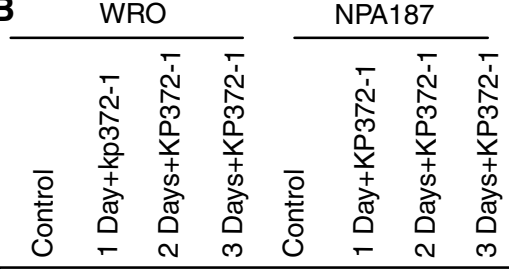

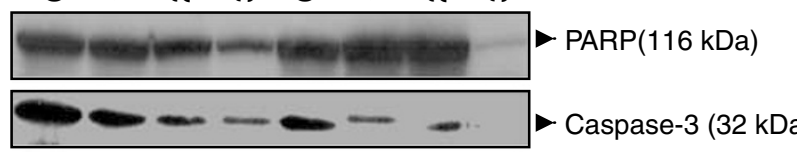

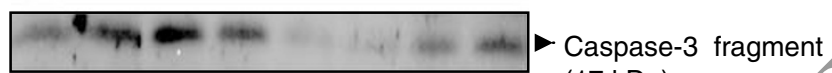
$(17 \mathrm{kDa})$

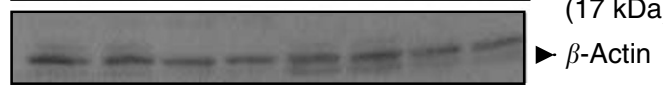

Figure 6 KP372-I induces apoptosis in thyroid cancer cell to vith Cells were treated with KP372-I as indicated for various eriods. D. fragmentation was measured by ethidium bromide staini ig a the DNA was resolved on an agarose gel. (B) Cells were treated with $172-1$ for different time periods, and cell extracts were in munoblotted the indicated antibodies. Results shown are represe tative of three experiments with similar results.

Inhibition of Akt might be of grtat it to patients with aggressive thyroid cancers, sup ort for the concept of targeting Akt comes from man obser ations. First, more than $54 \%$ of human cancers ha ${ }^{2}$. Th thetable in situ (Bellacosa et al, 1991\% Akt a vation was identified in 10 of 10 follicular cancers, $\angle$ of 26 p s illary cancers, and two of 10 follicular variants of illary cancers, but in only four of 66 normal tissue samples a two of 10 typical benign follicular adenomas (ask et al, 2004). Second, pAkt expression was found to be greates regic $s$ of capsular invasion and was localised to the nv $s$ in "calar cancers and to the cytoplasm in papillary car rs, ( cept for invasive regions of papillary cancers, where it loca d compartments (Vasko et al, 2004). Thus, smallmolecu $4 \mathrm{kt}$ inhibitors could have wide applicability as anticancer drugs. Th, rd, inhibition of the PI3K/Akt pathway by biochemical or genetic means increases the efficacy of chemotherapy, radiotherapy, or both, in vitro and in vivo (Hu et al, 2000; Brognard et al, 2001; Bondar et al, 2002). Finally, several standard chemotherapeutic and chemopreventive agents inhibit the PI3K/ Akt pathway when administered in vitro, and, in some cases, inhibition of Akt is directly responsible for these agents' cytotoxicity (West et al, 2002).

Despite the acknowledged need for Akt inhibitors, none is widely available and none that inhibits the kinase activity of Akt is
A

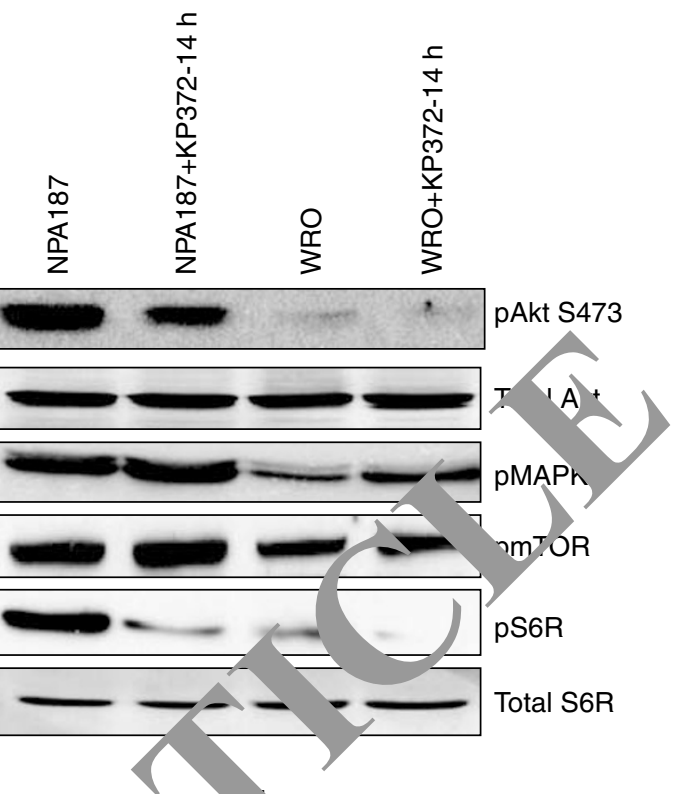

B
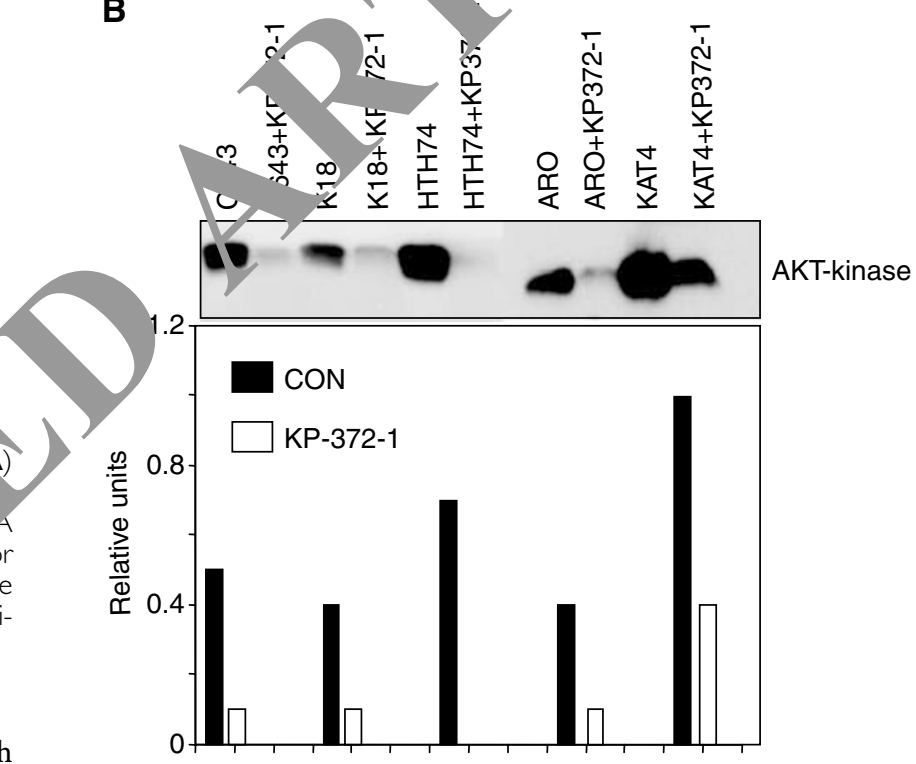

Figure 7 KP372-I inhibits Akt phosphorylation and some of the downstream signalling molecules as well as Akt kinase activity. (A) NPAI 87 and WRO cells were treated with the $I C_{50}$ concentrations of KP372-I (30-60 nM, respectively) for $4 \mathrm{~h}$ in RPMI medium without serum. Equal amounts of protein were resolved by SDS-polyacrylamide gel electrophoresis and immunoblotted with different antibodies as indicated. (B) KP372-I inhibits Akt kinase activity. Different thyroid cancer cells were treated with KP372-I for $2 \mathrm{~h}$, cell lysates were prepared, and Akt was immunoprecipitated and analysed for Akt-Ser473 and Akt kinase activity using an in vitro kinase assay with GSK- $\beta$ as a substrate. Results shown are representative of three experiments.

in clinical evaluation. The current studies indicate that KP372-1 acts to inhibit Akt and has activity in cells with high levels of pAkt. This is similar to other inhibitors of the PI3K/Akt pathway, such as Wortmannin and LY294002. Wortmannin and LY294002 may have limited clinical utility because they lack specificity and have potential adverse side effects, poor pharmacological properties, low stability, and poor solubility (West et al, 2002). Wortmannin inhibits myosin light-chain kinase; phospholipases $\mathrm{C}, \mathrm{D}$, and $\mathrm{A}_{2}$; and DNA-dependent protein kinase (West et al, 2002). LY294002 also inhibits the aryl hydrocarbon receptor, a ligand-activated 
transcription factor (Guo et al, 2000). In vivo use of LY294002 in mice has been associated with many adverse effects, including death ( $\mathrm{Hu}$ et al, 2002). Similarly, Wortmannin has demonstrated hepatic and haematopoietic toxicity. Therefore, although Wortmannin and LY294002 inhibit the PI3K/Akt pathway, their drawbacks raise doubts about their suitability as leading candidates for additional development.

The major advantage of KP372-1 over Wortmannin and LY294002 as PI3K inhibitors is its greater efficacy and the marked induction of apoptosis in cancer cell lines. This may be due to its targeting a central downstream molecule and also due to the potential for a number of processes to bypass effects at the level of PI3K. However, the final determination will be in terms of therapeutic index, which will need to be evaluated in mice and eventually humans. Indeed, a potential downside of Akt inhibitors is toxicity because of the importance of Akt signalling in many normal cellular processes such as insulin signalling, and the lack of selectivity of the current Akt inhibitors including KP372-1 to different Akt isoforms. Identifying kinase inhibitors that target the ATP-binding site of a kinase can be fraught with specificity problems because all kinases and many other molecules possess ATP-binding sites. This was perhaps best observed with STI-571 (Gleevec, imatinib mesylate, Novartis Pharma, Basel, Switzerland), a competitive inhibitor of the ATP-binding site of many kinases

\section{REFERENCES}

Bellacosa A, Testa JR, Staal SP, Tsichlis PN (1991) A retroviral oncogene, Akt, encoding a serine-threonine kinase containing an SH2-like region. Science 254: 274-277

Bondar VM, Sweeney-Gotsch B, Andreeff M, Mills GB, McConkey DJ (2002) Inhibition of the phosphatidylinositol $3^{\prime}$-kinase-AKT pathway induces apoptosis in pancreatic carcinoma cells in vitro and in vivo. Mol Carcer Ther 1: 989-997

Borrello MG, Pelicci G, Arighi E, De Filippis L, Greco A, Bongnrzo. Rizzetti M, Pelicci PG, Pierotti MA (1994) The oncogenic ver lons of ti Ret and Trk tyrosine kinases bind Shc and Grb2 ada proteins. Oncogene 9: 1661-1668

Brognard J, Clark AS, Ni Y, Dennis PA (2001) Akt/rotein kina $\%$ is constitutively active in non-small cell lung canc cells and promotes cellular survival and resistance to chemotherapy nd radiation. Cancer Res 61: 3986-3997

Coulonval K, Vandeput F, Stein RC, Kozma SC, Lamy _. _ont JE (2000) Phosphatidylinositol 3-kinase, protein kina nd ribosomal S6 kinases in the stimulation of thyroid epithelial cell pre cion by cAMP and growth factors in the presence of $\mathrm{j} \quad$ in. Bio lem 3 348(Part 2): 351-358

Dahia PL, Marsh DJ, Zheng Z, Zed nius Komm voth P, Frisk T, Wallin G, Parsons R, Longy M, Larsson E , Somatic deletions and mutations in the Cowde disea gene, PTEN, in sporadic thyroid tumors. Cancer Res 57. $10-4713$

Fagin JA (2002) Minir viev randed from the start - distinct oncogenic initiating events may de ine tumor fate in the thyroid. Mol Endocrinol 16:, $03-911$

Guo M, Joiak: A, Reiners Jr JJ (2000) Suppression of 2, 3, 7, 8tetrachlorodibe $p$-dio in (TCDD)-mediated aryl hydrocarbon receptor tra nation CYP1A1 induction by the phosphatidylinositol 3-kj se il ibitor -(4-morpholinyl)-8-phenyl-4H-1-benzopyran-4-one (LY2) 12, cem Pharmacol 60: 635-642

Heinrich Griffith DJ, Druker BJ, Wait CL, Ott KA, Zigler AJ (2000) Inhibition c-kit receptor tyrosine kinase activity by STI 571, a selective tyrosine kinase inhibitor. Blood 96: 925-932

$\mathrm{Hu}$ L, Hofmann J, Lu Y, Mills GB, Jaffe RB (2002) Inhibition of phosphatidylinositol $3^{\prime}$-kinase increases efficacy of paclitaxel in in vitro and in vivo ovarian cancer models. Cancer Res 62: 1087-1092

Hu L, Zaloudek C, Mills GB, Gray J, Jaffe RB (2000) In vivo and in vitro ovarian carcinoma growth inhibition by a phosphatidylinositol 3-kinase inhibitor (LY294002). Clin Cancer Res 6: 880-886

Jemal A, Tiwari RC, Murray T, Ghafoor A, Samuels A, Ward E, Feuer EJ, Thun MJ (2004) Cancer statistics, 2004. CA Cancer J Clin 54: 8-29
(Klejman et al, 2002). The wide clinical application of STI-571 is partially due to its ability to inhibit many kinases, including bcrabl, platelet-derived growth factor receptors, and c-Kit (Heinrich et al, 2000; McGary et al, 2002; von Bubnoff et al, 2002). The relatively nonspecific activity of STI-571 results in activity against Kit and the PDGFR in gastrointestinal stromal tumours (GIST) and against the PDGFR in hypereosinophilic syndrome. It is somewhat surprising and fortuitous that the relative broad activity of STI-571 was not associated with toxicity.

In conclusion, thyroid cancer cell lines and well-differentiated human tumour specimens showed high levels of Akt $\mathrm{p}^{\mathrm{l}}$ osphorylation on Ser473 and high Akt activity levels, which oo ted the findings of several other studies (Dahia et al, 1997; Liam $a l, 10,7$; Ringel et al, 2001), indicating that the Akt sign flling path a role in thyroid cancer progression. $I$ additiol specific inhibition of Akt kinase activity by KP37) 1 res ed in decreased cell proliferation and induction of apor osis of thy a cancer cells in vitro. Although anaplastic thyroid cell lines were included in some of our experiments, our da $\mathrm{d}^{+}$len uppor to the use of Akt kinase inhibitor in well-differen ed t.., carcinoma rather than in anaplastic or poory diffe tiated thyroid carcinomas. These findings indicate $t_{1}$ further $\mathrm{p}$-clinical evaluation of this and other compounds arge the PI3K/Akt pathway in welldifferentiated thyroi ancer is rranted. 